Verständigung zwischen dem deutschen und dem amerikanischen Volk geleistet hat, mehr als ein Dutzend Diplomaten vermochten. Das würdigte auch unser Bundespräsident Theodor Heuss durch die Verleihung des Großen Verdienstkreuzes der Bundesrepublik und durch seinen Besuch bei ScHENCK in Lindenfels.

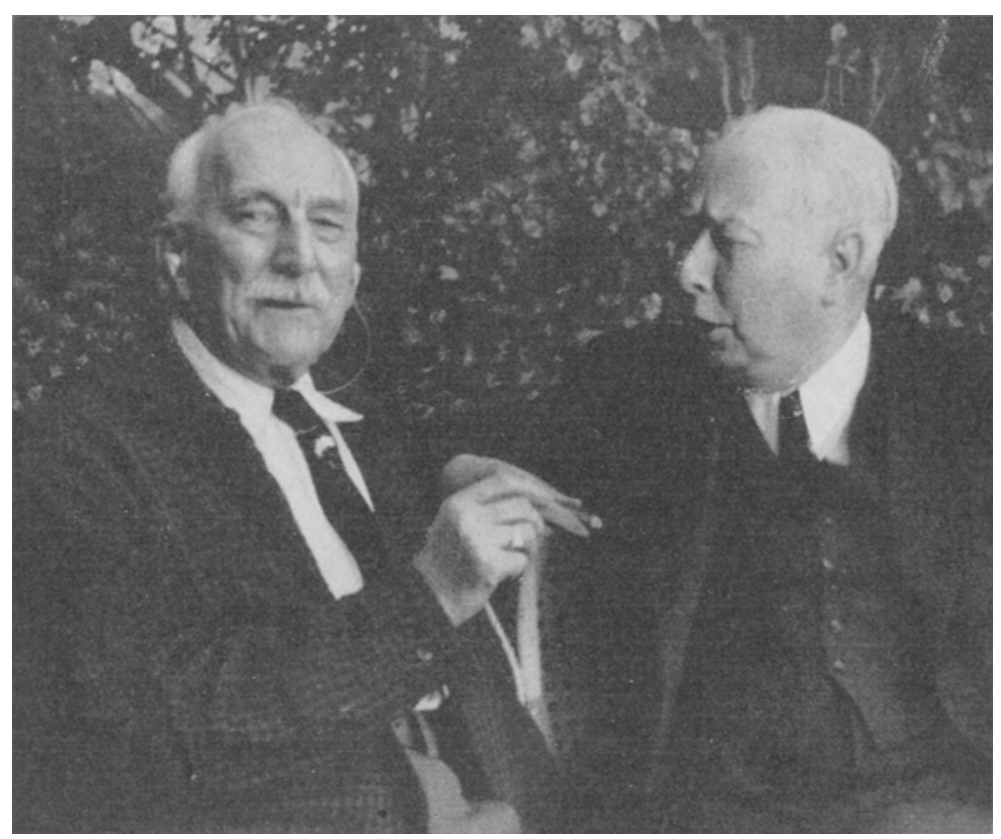

Lindenfels. Odw. Juli 1953

C. A. SCHENCKs Andenken wird in zwei Weltteilen und nicht nur von den Forstleuten in hohen Ehren gehalten werden ${ }^{2}$.

L. FABRICIUS

\title{
Dozent Dr. R. B. Hilf verstorben
}

Am 3. September 1955 verstarb im Klagenfurt völlig unerwartet Forstmeister Dozent Dr. oec. publ. Richard Berthold Hilf, Direktor des Forstgeschichtlichen Instituts der Universität Freiburg i. Br. Dr. R. B. Hilf befand sich zum Zwecke forstgeschichtlicher Archivstudien in Osterreich.

Der Internationale Ring der Jagdwissenschaftler hält seine diesjährige Tagung in der Zeit vom 28. bis 31. Oktober in Graz gemeinsam mit dem Osterreichischen Arbeitskreis für Wildtierforschung $a b$.

Näheres im Heft 2 der Zeirschrift für Jagdwissenschaft oder über Professor Nüßlein, Institut für Jagdkunde in (20b) Hann.-Münden, oder Osterreichischer Arbeitskreis für. Wildtierforschung in Graz, Ballhausgasse 3.

2 Viel Wissenswertes über ScHENCK, für das hier kein Platz mehr war, findet sich in der Allgemeinen Forstzeitschrift Jahrgang 1951 (aus der Feder von Strehlke); Jahrgang 1951 S. 466; Jahrgang 1953 S. 151; Jahrgang 1954 S. 214; Jahrgang 1955 (von Hesse). 